Z. klin. Chem. u. klin. Biochem.

7. Jg., S. 18-24, Januar 1969

\title{
Zur Bestimmung der 5'-Nucleotidase im Serum
}

\author{
Von J. BeCKJLANN, K. LEYBold und L. WeISBECKER \\ Aus der II. Mediziniscben Klinik und Poliklinik der Universität Kiel (Direktor: Prof. Dr. L. Weisbecker)
}

(Eingegangen am 8. August 1968)

\begin{abstract}
Mit dem Ziel, eine möglichst richtige und einfache $5^{\prime}$-Nüucleotidase-Bestimmung im Serum aufzubauen, haben wir zahlreiche Literaturangaben experimentell überprüft und optimale Reakrionsbedingungen ermittelt. Es wird ein Vorschlag gemachr, die nicht durch $5^{\prime}-$ Nucleotidase bedingte Phosphathydrolyse des Substrates 5 -AMIP korrekt abzugrenzen. Als günstigste Reaktionsbedingungen erweisen

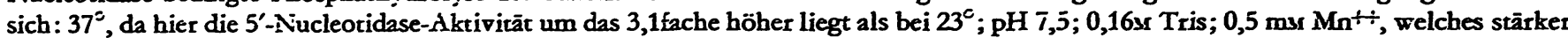
als $\mathrm{Mg} \div$ aktiviert; 0,1 mss $5^{\prime}$-AMP, da ab $0,12 \mathrm{~ms}$ Substrathemmung auftritt. Zur Abgrenzung der unspezifischen Phosphathydrolyse eignet sich ein Substratgemisch von 2'-AMP und 3'-AMP, im Parallelansatz inkubiert, besser als andere Verfahren, in denen z. B. EDTA zur selektiven Hemmung der alkalischen Phosphatase oder $\mathrm{Ni} \div \div$ zur selektiven Hemmung der $5^{\prime}$-Nucleotidase benutzt werden. Eine Methode, die 5'-Nucleotidase-Akrivitāt mittels Phosphatanalyse zu bestimmen, wird vorgeschlagen. Die zeitraubende Endpunktbestimmung kann aber mit einem kinetischen UV-Test, der in der folgenden Arbeit ausführlicher beschrieben wird, umgangen werden.
\end{abstract}

\section{The measurement of serum 5'-nucleotidase}

In order to develope an accurare and simple method for the determination of the $5^{\prime}$-nucleotidase in serum, numerous methods in literature were tested experimentally, and the optimum conditions were determined. A proposal is made for an accurate subtraction of the non-specific hydrolysis of the substrate $5^{\prime}$-AMIP. The most suitable conditions of reactivity are: $37^{\circ} \mathrm{C}$, for at this temperature the $5^{\prime}-$ nucleotidase-activity is 3.1 times higher than at the $23^{\circ} \mathrm{C}$-level; $\mathrm{pH} 7.5 ; 0.16 \mathrm{~s}$ tris; $0.5 \mathrm{mu} \mathrm{Mn}^{+\div}+$, which activates more intensely than $\mathrm{Mg} \div ; 0.1 \mathrm{mss} 5^{\prime}$-AMP, since abore $0.12 \mathrm{~ms} 5^{\prime}$-AMP, substrate inhibiton occurs. For the subtraction of the non-specific phosphatehydrolysis, the use of a substrate-mixture of $2^{\prime}-A M I P$ and $3^{\prime}$-ANIP is more suitable than EDTA for selectire inhibition of alkaline phosphatases, or $\mathrm{Ni} \div$ for selective inhibiton of the $5^{\prime}$-nucleoridase, which are used in other methods. The mixture is incubated in a parallel control test. A method for the determination of the 5 -nucleotidase-activity by phosphate analysis is suggested. Instead of this time-consuming method a kinetic UV-test can be used. It is described in detail in the following paper.

Die Bestimmung der $5^{\prime}-$ Nucleotidase $\left.^{1}\right)$ im Serum wird wegen ihres empfindlichen Ansprechens bei hepatobiliären Erkrankungen und ihrer Spezifität in zunehmendem Maße der Bestimmung der alkalischen Phosphatase oder der Leucin-Aminopeptidase vorgezogen (1-6). Differentialdiagnostisch ermöglicht sie den Ausschluß eines osteoblastischen Knochenprozesses, der mit AP-Erhöhung im Serum einhergeht $(1,2$, 5-12). Eine erhöhte Serum-5'-NTD kann unter Umstānden den einzigen Hinweis auf Lebermetastasen, Pericholangitis, Intoxikation, Fettleber, kardiale Stauung oder sonstige leichte Behinderungen des Gallenabflusses geben $(4,6)$. Thre fortlaufende Bestimmung eignet sich ferner gut zur Verlaufskontrolle (13).

Die $5^{\prime}$-NTD-Aktivitāt wird im allgemeinen an Hand der Phosphathydrolyse des Adeninmononucleotides 5'AMP beim $\mathrm{pH}-\mathrm{Optimum}$ 7,5 ermittelt. Eine richtige Bestimmung muß die bei diesem $\mathrm{pH}$ ebenfalls noch vorhandene Aktivität unspezifischer Phosphatasen im Serum berücksichtigen. Die Richtigkeit wird bei den genannten Untersuchern $(1-13) z$. T. wesentlich durch die unexakte Abgrenzung der letzteren von der 5'-NTD beeintrāchtigt. Die Prāzision leidet in jedem Falle unter der methodischen Ungenauigkeit der relativ umstāndlichen Phosphatbestimmung. Überdies ist die für die Vorinkubation von Serum mit 5'-AMP erforderliche Zeit $(1 / 2-21 / 2$ Std.) erheblich. Aus diesen Gründen hat sich die 5'-NTD-Bestimmung im Serum bislang

1) Enzyme: 5'-NTD = 5-Ribonucleotid-Phosphohydrolase (EC 3.1.3.5); $\mathrm{AP}=$ Alkalische Phosphatase = Orthophosphatmonoester-Phosphohydrolase (EC 3.1.3.1); $\mathrm{ADA}=$ Adenosindesaminase $=$ Adenosin-Aminohydrolase (EC 3.5.4.4). nur vereinzelt durchgesetzt. Den zahlreichen bisher entwickelten methodischen Variationen zur Abgreńzung unspezifischer Phosphatasen im Serum von der 5'-NTD liegen 5 prinzipielle Möglichkeiten zugrunde:

1. Die Aktivitāt der unspezifischen P̈hosphatasen wird mit einem von der 5'-NTD nicht hydrolysierten Phosphatester gesondert ermittelt und von der Gesamthydrolyse von $5^{\prime}$-AMP subtrahiert $(4,6-10)$.

2. Die Aktivitāt der unspezifischen Phosphatasen beim $\mathrm{pH}$ des $5^{\prime}$-NTD-Testes wird vernachlässigt (3).

3. Selektive Hemmung unspezifischerPhosphatasen (1,2). 4. Messung der enzymatischen Phosphathydrolyse mit und ohne Hemmung der $5^{\prime}$-NTD durch Nickelionen (Differenzbestimmung) $(5,11-14)$.

5. Es wird ausgenutzt, dəB Histidin bei $\mathrm{pH} 8,5$ die 5'-NTD aktiviert und die AP geringfügig hemmt. Steigt nach Histidinzusatz die Gesamtphosphathydrolyse, so ist das 5'-NTD/AP-Verhältnis erhöht; sinkt sie, so ist es vermindert (15).

Um die Methodik zu verbessem, haben wir in dieser Arbeit optimale Reaktionsbedingungen ausgearbeitet und uns besonders der Frage der richtigen Abgrenzung der spezifischen und unspezifischen Phosphataseaktivitäten zugewandt. In der folgenden Arbeit beschreiben wir eine Möglichkeit, die 5'-NTD im Serum empfindlicher, genauer und schneller zu bestimmen (16).

\section{Material und Methoden}

Um Einflüsse auf die 5'-NTD-Aktivität zu studieren, haben wir Seren mit hoher, routinemäßig im klinisch-chemischen Laboratorium bestimmter AP ausgewählt, in denen auch hohe 5'-NTD- 
Aktivität nachweisbar war. Außerdem haben wir aus Aorta vom Menschen nach Armed und Reis (17) eine praktisch AP-freic 5'-NTD präpariert. Zur Photometrie haben wir ein Eppendorfgerät mit Multiplier und ein Spektralphotometer PMQ II der Pa. Zciss, Oberkochen, verwendet.

5'-AMP, Adenosindesaminase $10 \mathrm{mg} / \mathrm{ml}$, und Tris von Fa. Boehringer, Mannheim; Glycylglycin von $\mathbf{P a}$. Th. Schuchardt, München, 2'-AMP und $3^{\prime}$-AMP im Gemisch $\left(2^{\prime}-+3^{\prime}\right.$-AMP), (z. B. Mcrck Nr. 869), Adenosin, $\mathrm{NiCl}_{2}, \mathrm{MnSO}_{4}, \mathrm{MgCl}_{2}, \mathrm{Na}_{2} \mathrm{~S}_{2} \mathrm{O}_{5}$, $\mathrm{H}_{2} \mathrm{SO}_{4}, \mathrm{HCl}, \mathrm{NaOH}, \mathrm{CH}_{3} \mathrm{COOH},\left(\mathrm{NH}_{2} \mathrm{SO}_{4}\right.$, Triäthanolamin, Barbital-Natrium, Natrium- $\beta$-Glycetophosphat, di-Natriumphenylphosphat, EDTA, di-Natriumtartrat, Trichloressigsäure, 4Mcthylaminophenolsulfat (Metol) und Ammoniummolybdat von Pa. E. Merck, Darmstadt, soweit vorhanden in p. a.-Qualität, ferner Reagenziensätze zur Bestimmung der sauren Phosphatase (SP) und zur kinctischen AP-Bestimmung (Merckotest).

Dic Geschwindigkeit der 5'-AMP-Hydrolyse haben wir durch Bestimmung beider Spaltprodukte $\left(\mathrm{P}_{i}\right.$ und Adenosin) ermittelt. Phosphorsäure haben wir nach LoHManN und Jendrassik (18) mit Mctol als Reduktionsmittel bestimmt, Adenosin nach KALCKAR (19). AP haben wir nach RICK und Mitarbeitern $(20,21)$ und durch Bestimmung des freigesetzten Phosphats, SP nach ANDersCH und SzCYpinsky (22) gemessen. In jedem Falle haben wir Doppelbestimmungen durchgeführt. Leerwerte erhalten wir, indem wir die enzymhaltige Iösung (Scrum, Aortenextrakt) nach Ablauf der Inkubationszeit und Zugabe von Trichloressigsäure zur Substratlösung pipettieren.

Um zu ciner wenig aufwendigen kinetischen Bestimmung der $5^{\prime}$-NT'D-A ktivität zu gelangen, haben wir den UV-Test nach Kalckar (19), den Segal und Brenner (23) für Rattenlebermikrosomen und Ipata (24) für Schafhirnextrakt cingesetzt haben, modifiziert und auf Serum übertragen. In diesem 'Test wird 5'AMP als Substrat verwendet. Es wird in Adenosin und $\mathrm{P} i$ gespalten. Adenosin wird von zugesetzter ADA zu Inosin desaminicrt.

$$
\begin{aligned}
& \text { 5'-AMP } \stackrel{\text { 5'-NTD }}{\longrightarrow} \text { Adenosin }+\mathrm{P}_{i} \\
& \text { Adenosin }+\mathrm{H}_{2} \mathrm{O} \stackrel{\text { ADA }}{\longrightarrow} \text { Inosin }+\mathrm{NH}_{3}
\end{aligned}
$$

Die letztere Reaktion ist besonders empfindlich durch den Extinktionsabfall bei $265 \mathrm{~nm}$ meßbar, dem Maximum des Differenzspektrums Adenosin-Inosin. An Hand des Extinktionskocffizienten dieser Reaktion $\left(\Delta \varepsilon=8,69 \mathrm{~cm}^{2} / \mu \mathrm{Mol}\right)$ berechnen wir dic $\mu$ Mole des gespaltenen $5^{\prime}$-AMP (23). IPATA hat über einen weiten Aktivitätsbereich strenge Proportionalität zwischen dieser MeBgröße und der 5'-AMP-Hydrolyse nachgewiesen (24).

Dieser kinetische Test wird in $1 \mathrm{~cm}$ Quarzküvetten in einem Endvolumen von $3,12 \mathrm{ml}$ bei $265 \mathrm{~nm}$ durchgeführt. Die Bandbrcite soll $0,9 \mathrm{~nm}(=0,2 \mathrm{~mm}$ Spaltbreite) nicht überschreiten. $A b 0,2 \mathrm{~mm}$ haben wir mit wachsender Spaltbreite verringerte AMP-Absorption zufolge mangelhafter Monochromasic gemessen.

\section{Ergebnisse und Bewertung}

\section{Temperatur}

Die üblicherweise verwendete Temperatur von $37^{\circ}$ haben wir übernommen $(7,14,15)$. Es lohnt sich, die Nachteile der Messung bei $37^{\circ}$ in Kauf zu nehmen. Wir haben ähnlich wie Levin und BoDansky (25) gefunden, daß die Aktivität gegenüber $23^{\circ}$ um das 3,1fache höher liegt.

\section{pH-Wert}

Der von den meisten Autoren eingehaltene $\mathrm{pH}-$ Wert von $7,5(2,7,14)$ erweist sich als sehr geeignet (s. $\mathrm{Abb}$. 1). Er liegt für die 5'-NTD gerade noch im op- timalen Bereich, während die unspezifische 5'-AMPHydrolyse im Serum bei pH 7,5 gegenüber anderen pH-Werten relativ sehr gering ist $(7,15,24,26,27)$.

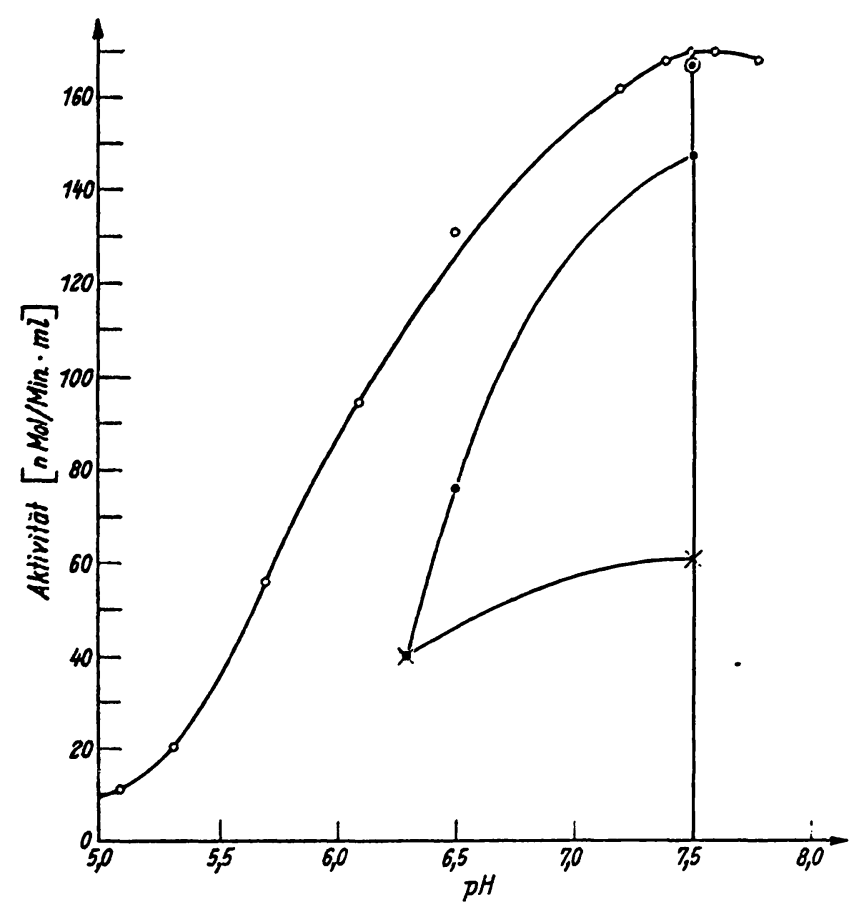

Abb. 1

5'-NTD-Aktivităt (nMol 5'-AMP/Min. $m$ m hydrolysiert) zwischen pH 5,1 und 7,8 und Einfluß von $\mathrm{Mn}^{++}$und $\mathrm{Mg}^{++} \circ{ }^{\circ} \longrightarrow 0,5 \mathrm{mM}$

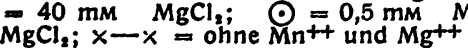

Testansatz: $\mathrm{pH}$ und Aktivatoren wie bezeichnet; $0,16 \mathrm{M}$ Tris- $\mathrm{HCl}$ bzw. Tris-Acetat; sonst wie Abb. 2

\section{Puffer}

Wir verwenden Tris, pH 7,5. In Tris zeigt das Enzym bei diesem $\mathrm{pH}$ eine deutlich, wenn auch geringfügig höhere Aktivität als in Triäthanolamin und Glycylglycin, die prinzipiell auch geeignet sind, da sie UVLicht nicht absorbieren und die 5'-NTD nicht hemmen. Die Konzentration des Tris-Puffers ist von Bedeutung. Seren mit erhöhter 5'-NTD-Aktivität weisen oft abnorme Proteinverhältnisse auf, bei denen wir Veränderungen der optischen Dichte bei $265 \mathrm{~nm}$ messen, die unterhalb von $0,12 \mathrm{M}$ Tris zunehmend als steigender und oberhalb $0,18 \mathrm{M}$ Tris zunehmend als fallender „Leerschleich“ imponieren. Wir verwenden als Endkonzentration $0,16 \mathrm{M}$ Tris. Diese Konzentration gewährleistet in jedem Falle pH-Konstanz während des Testverlaufs. Im übrigen haben wir in $0,16 \mathrm{M}$ Tris regelmäßig eine um 7\% höhere. Aktivität als in $0,04 \mathrm{M}$ Tris gemessen.

\section{Co-Faktoren}

$\mathrm{Mn}^{++}$aktiviert die $5^{\prime}-\mathrm{NTD}$ stärker als $\mathrm{Mg}^{++}(17,28)$. Bei ausreichender $\mathrm{Mn}^{++}-\mathrm{Konzentration}$ wird $\mathrm{Mg}^{++}$ Zusatz überflüssig. Bezeichnen wir die 5'-NTD-Aktivität eines Mischserums bei $\mathrm{pH}$ 7,5 ohne Ionenzusatz mit 1 , so beträgt sie mit $40 \mathrm{mM} \mathrm{Mg} \mathrm{Mg}^{++}$(2) 2,5 , mit $0,5 \mathrm{~mm} \mathrm{Mn++} \mathrm{2,8} \mathrm{und} \mathrm{mit} \mathrm{beiden} \mathrm{Ionen} \mathrm{in} \mathrm{den} \mathrm{ge-}$ nannten Konzentrationen ebenfalls 2,8 (vgl. Abb. 1). 


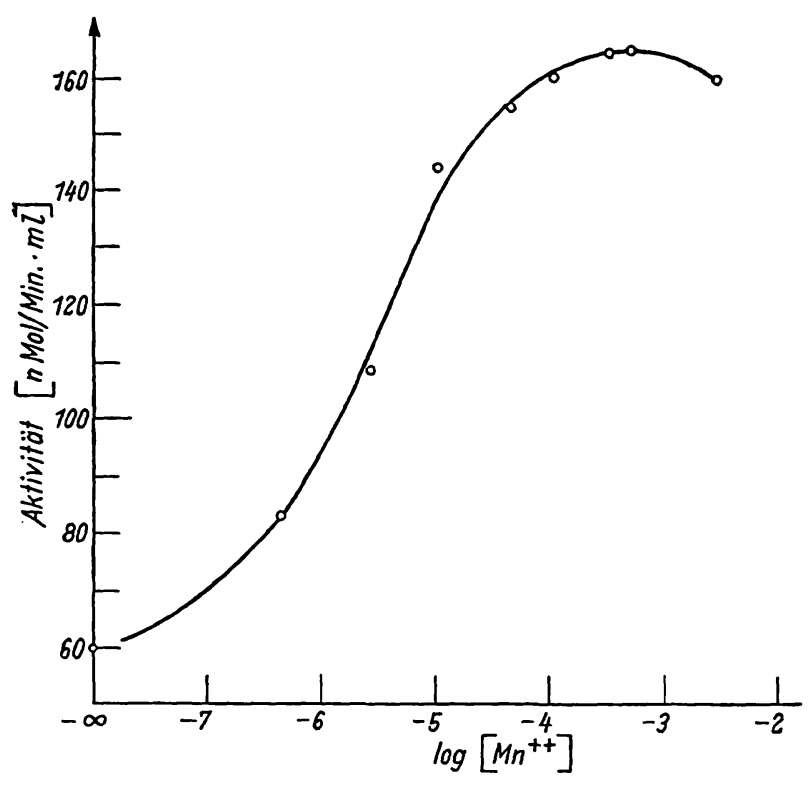

Abb. 2

Einfluß verschiedener Mn+t-Konzentrationen auf die 5'-NTD-Aktivität (nMol 5'-AMP/Min. - $\mathrm{ml}$ hydrolysiert)

Testansatz: MnSO, wie bezeichnet; Vol. $3,12 \mathrm{ml}$; Temp. $37^{\circ} ; 0,16 \mathrm{M}$ Tris pH 7,5;0,1 mM 5'-AMP: $5 \mu \mathrm{g}$ ADA in $20 \mu \mathrm{l} 2,7 \mathrm{M}\left(\mathrm{NH}_{3}\right)_{2} \mathrm{SO}_{4} ; 0,1 \mathrm{ml}$ Mischserum mit hoher 5'-NTD-Aktivität (unspez. Phosphatasen bei pH 7,8 kaum meßbar)

Die optimale $\mathrm{Mn}^{++}$-Konzentration ist 0,5 mM (s. Abb. 2). In dieser Konzentration beeinflußt $\mathrm{Mn}^{++}$die unspezifischen alkalischen Phosphatasen im Serum praktisch nicht.

\section{Substratkonzentration}

Bei der Wahl der Substratkonzentration sind 5'-AMPSättigungskonzentration, Substrathemmung und, speziell im UV-Test, die hohe UV-Absorption des Nucleotides zu berücksichtigen. Wir haben in Mischserum mit hoher 5'-NTD-Aktivität die Abhängigkeit der Aktivität ron der 5'-AMP-Konzentration bestimmt. Die graphische Darstellung nach LINEveaver und Burk (29) läßt die günstigste Substratkonzentration sowie eine deutliche Substrathemmung erkennen. Als Michaeliskonstante haben wir $11 \mu \mathrm{M}$ ermittelt. Überschreitung von $120 \mu \mathrm{M} 5^{\prime}$-AMP verbietet sich wegen Substrathemmung (s. Abb. 3). Wir verwenden $0,1 \mathrm{~mm}$

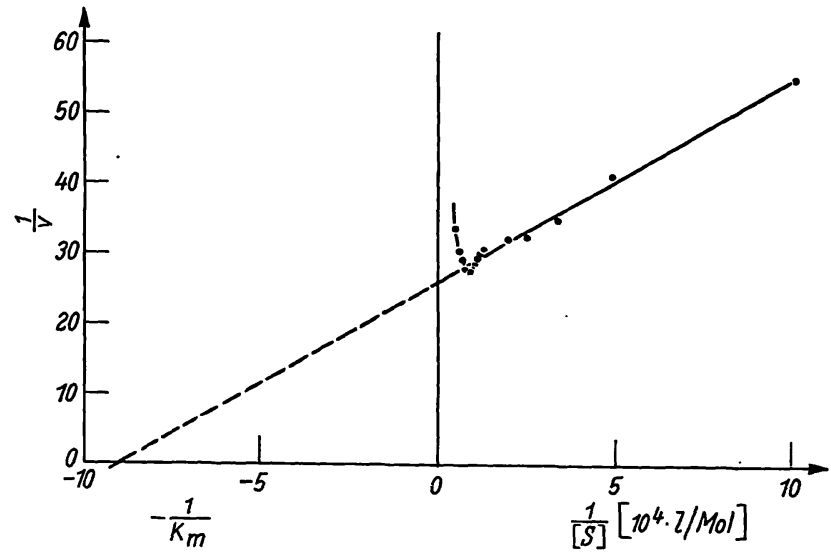

Abb. 3

Reziproke 5'-NTD-Aktivität $\left(\left(\Delta \mathrm{E}_{208} / \mathrm{Min}^{\prime}\right)^{-1}\right)$ in Abhängigkeit von der reziproken 5'-AMP-Konzentration und Micheliskonstante (Lineweaver-Burk)

Testansatz: Substrat s. Abszisse; 0,5 mM MnSO, $0,02 \mathrm{ml}$ Mischserum mit sehr hoher $5^{\prime}$-NTD- und geringer AP-Aktivität; sonst wie
5'-AMP. Bei dieser Konzentration ist die Gesamtabsorption von 5'-AMP und UV-absorbierenden Serumbestandteilen (Protein, Bilirubin) noch ausreichend niedrig, so $\mathrm{daB}$ im Spektralphotometer gemessen werden kann. Wir erreichen mit 0,1 mM 5'-AMP 97\% der praktisch erreichbaren - das sind 90\% der theoretischen - Maximalgeschwindigkeit (vgl. Abb. 3). Die Extinktionsabnahme pro Minute ist der Enzymkonzentration proportional, wenn sie 0,075 nicht überschreitet (kinetischer Test übèr maximal 5 Min.).

\section{Indikatorenz ym Adenosindesaminase}

ADA wird von $0,5 \mathrm{~mm} \mathrm{Mn}^{++}$um $15 \%$ gehemmt. Die von uns im Test verwendete Menge, $5 \mu \mathrm{g} A D A$ in $20 \mu l 2,7 \mathrm{M}\left(\mathrm{NH}_{4}\right)_{2} \mathrm{SO}_{4}$, ermöglicht aber eine praktisch nicht mehr zu steigernde. Desaminierung des durch die 5'-NTD freigesetzten Adenosins.

\section{Ausscbluß von AMP-Desaminase, Erytbrocyten- und Pro- stataphosphataseaktivitäten}

Bestimmt man 5'-NTD in Gegenwart von $16 \mathrm{~mm}$ EDTA, das die AP und die 5'-NTD vollständig hemmt (12), oder mit einem $3 \mathrm{mg} / 100 \mathrm{ml}$ Hämoglobin enthaltenen Hämolysat aus gewaschenen Erythrocyten, die relativ viel AMP-Desaminase und saure Phosphatase enthalten, so läßt sich kein Extinktionsabfall bei $265 \mathrm{~nm}$ beobachten. Daraus folgt, daß wir in unserem Test praktisch keine AMP-Desaminase- und Erythrocyténphosphataseaktivitäten messen (beide werden durch EDTA nicht beeinflußt).

Saure Phosphatase im Serum kann sich durch unspezifische Hydrolyse in unserem Test nur bei extremer Erhöhung infolge Prostata-Carcinoms auswirken (s. 1. c. 16).

\section{Haltbarkeit der Serum- $5^{\prime}-N T D$}

Serum-5'-NTD wird außerordentlich langsam inaktiviert, wenn man das Serum bei $0^{\circ}-4^{\circ}$ im Kühlschrank aufbewahrt. Im Mittel haben wir innerhalb von 3 bis 6 Monaten einen Aktivitätsverlust von 3-8\% gefunden.

Im folgenden Abschnitt verwenden wir die oben beschriebene Methodik zur Prüfung der bisher in der Literatur angegebenen Möglichkeiten zur Abgrenzung der unspezifischen Phosphathydrolyse und beschreiben ein besseres Verfahren (vgl. Einleitung Nr. 1-5):

\section{Vergleichssubstrat}

Werden zur Erfassung des Anteils der unspezifischen Phosphathydrolyse von 5'-AMP in einem Vergleichsansatz die von der 5'-NTD nicht gespaltenen Substrate $\beta$-Glycerophosphat $(7,28)$ oder Phenylphosphat $(7,26,27,30)$ verwendet, so wird vorausgesetzt, daß die unspezifischen Phosphatasen diese Stoffe bei $\mathrm{pH}$ 7,5 genau so schnell wie 5'-AMP hydrolysieren. Mehrere Autoren bemerken kritisch, daß diese Voraussetzung nicht erfüllt sei $(12,15,17)$. 
Als Vergleichssubstrat erweist sich $2^{\prime}-+3^{\prime}$-AMP als besonders geeignet; wir verwenden es für unsere Untersuchungen aus folgenden Gründen:

a) Die Hydrolyse dieses Substrates, welches von 5'NTD nicht gespalten wird $(28,31,32)$, ist in gleicher Weise wie die 5'-AMP-Spaltung im kinetischen UVTest mit ADA zu verfolgen, da ebenfalls Adenosin entsteht.

b) Von den unspezifischen Serumphosphatasen ist es im wesentlichen AP, die bei $\mathrm{pH}$ 7,5 5'-AMP noch hydrolysieren kann $(7,15)$. Aus kinetischen Untersuchungen anderer Autoren mit mehreren Substraten $(33,34,35)$ und eigenen Versuchen (vgl. Abb. 4 und Diskussion) geht hervor, daß sich gerade $2^{\prime}-+3^{\prime}$-AMP zur Bestimmung dieser unspezifischen Hydrolyse gut eignet.

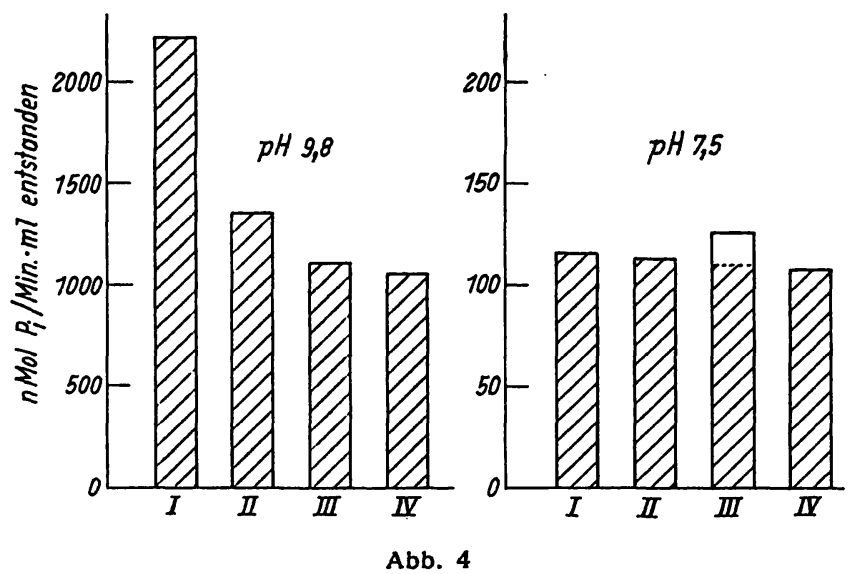

Vergleich der Hydrolyseraten verschiedener Phosphorsäureester durch Serum bei $\mathrm{pH} 9,8$ und 7,5. I = Phenylphosphat; II $=22^{\prime}-+3^{\prime}-A M P$;

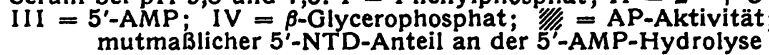

Testansatz: Vol. $2,0 \mathrm{ml}$; Temp. $37^{\circ}$; Konzentration der Phosphor-

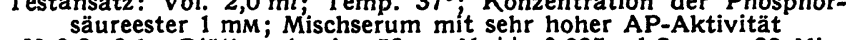
säureester $\mathrm{mM}$; Mischserum mit sehr hoher AP-Aktivität
pH 9,8: 0,1M Diäthanolamin; $50 \mu \mathrm{M} \mathrm{Mg} \mathrm{M}^{++}$; 0,025 ml Serum; $30 \mathrm{Min}$. pH 9,8: 0,1M Diathanolamin; $50 \mu \mathrm{M}$ inkubation

pH 7,5: 0,16M Tris; 0,5 mM Mn ${ }^{++} ; 0,1 \mathrm{ml}$ Serum; 180 Min. Inkubation

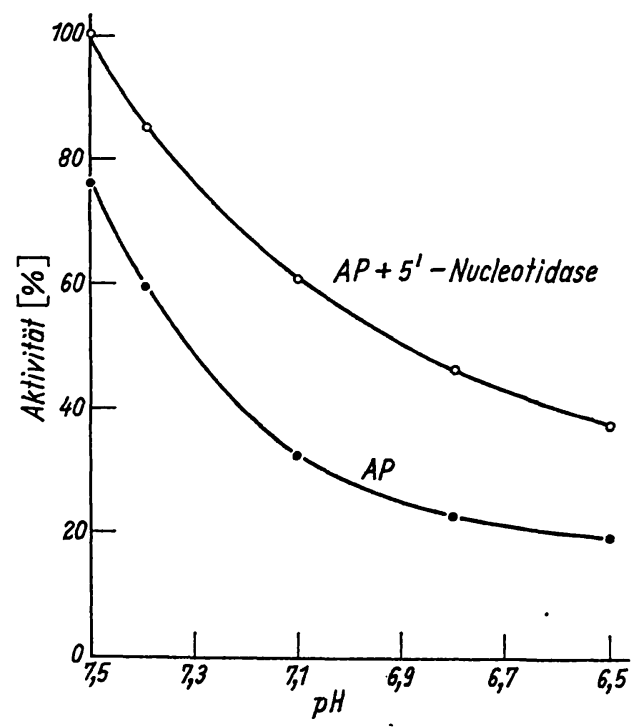

Abb. 5

Phosphathydrolyse bei verschiedenen pH-Werten am Beispiel eines Serums mit hoher AP- und relativ geringer 5'-NTD-Aktivität. 5'-
AMP-Hydrolyse/Min./ml bei $\mathrm{pH} \mathrm{7,5}$ gleich $100 \%$ gesetzt. $0-0=$ MP-Hydrolyse/Min./ml bei $\mathrm{pH} \mathrm{7,5}$ gleich $100 \%$ gesetzt. $\circ$
$0,1 \mathrm{mM} 5^{\prime}-\mathrm{AMP} ;-0,1 \mathrm{mM} 2^{\prime}-+3^{\prime}$-AMP als Substrat

Testansatz, $\mathrm{pH}$ und Substrat wie bezeichnet; $0,16 \mathrm{M}$ Tris- $\mathrm{HCl}$ bzw.

\section{Vernacblässigung unspezifiscber Phosphataseaktivitäten}

Abbildung 5 zeigt in einem typischen Beispiel, daß die unspezifische Phosphathydrolyse, besonders wenn die AP im Verhältnis zur 5'-NTD stark erhöht ist, z. B. bei osteoblastischem Knochenprozeß, nicht vernachlässigt werden darf. Die in Abbildung 5 beschriebene APAktivität betrug $2920 \mathrm{mU} / \mathrm{ml}$ im kinetischen Test nach RICK und Mitarbeitern $(20,21)$. Bliebe diese AP-Aktivität als solche unberücksichtigt und würde sie als 5'-NTD-Aktivität mitbewertet, so fiele der bei pH 7,5 gemessene $5^{\prime}$-NTD-Wert fast um das Fünffache zu hoch aus. BARDAwILL und ChaNG (3), die zwecks Verringerung des AP-Fehlers bei $\mathrm{pH}$ 7,3 messen, würden in unserem Beispiel einen $2 \frac{1}{2}$ fach $z u$ hohen $5^{\prime}$ NTD-Wert messen. Selbst bei niedrigeren $\mathrm{pH}$-Werten bis 6,5 ist in solchem Falle die AP gegenüber der 5'NTD nicht zu vernachlässigen.

\section{Selektive $A P$-Hemmung}

Nach Young ist eine selektive AP-Hemmung durch 1,5 mM EDTA möglich (2). Wichtige Voraussetzungen, unter denen die EDTA-Hemmung stattfindet, beschreibt Young nicht. Eine praktisch vollständige selektive AP-Hemmung durch EDTA ist auch nach unseren Versuchen möglich. Wir beschreiben im folgenden die von uns ermittelten Bedingungen zur selektiven AP-Hemmung in Mischserum mit hoher AP:

a) Das Serum muß verdünnt werden. Wir haben es zur Vorinkubation mit EDTA bei $37^{\circ} 1: 30$ mit $0,16 \mathrm{M}$ Tris $\mathrm{pH} 7,5$ verdünnt.

b) 1,5 mM EDTA und

c) $40 \mathrm{mM} \mathrm{MgCl} \mathrm{M}_{2}$ müssen bei der Vorinkubation zugegen sein.

d) Eine Hemmung der AP um $90 \%$ wird unter diesen Bedingungen in 2 Stdn. erreicht (s. Abb. 6).

Dabei bleibt die 5'-NTD-Aktivität voll erhalten. Wird $40 \mathrm{~mm} \mathrm{Mg} \mathrm{Mg}^{++}$nicht zur Vorinkubation, wohl aber im 5'-NTD-Test eingesetzt, so hemmt EDTA zwar die AP schneller, aber die $5^{\prime}$-NTD wird ebenfalls vollständig inaktiv (s. Abb. 7).

Die Vorinkubation von 2 Stdn. erscheint uns für einen einfachen Enzymtest zu lang. Außerdem kann $\mathrm{Mn}^{++}$,

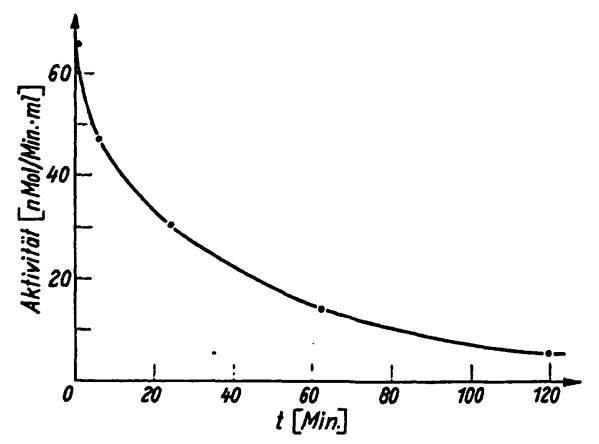

Abb. 6

AP-Aktivität (nMol 2'- + 3'-AMP/Min. $\cdot \mathrm{ml}$ hydrolysiert) in Abhängigkeit von der Dauer der Vorinkubation mit EDTA und $\mathrm{Mg}^{++}$ Im AP-Test; 1,5 mM EDTA; $40 \mathrm{mM} \mathrm{MgCl}_{2}$ (kein $\mathrm{Mn}^{++}$); $0,1 \mathrm{mM}$ $2^{\prime}$ - + 3'-AMP; 0,16M Tris-HCl; 0,1 ml Mischserum mit sehr hoher AP-Aktivität; sonst wie Abb. 2 


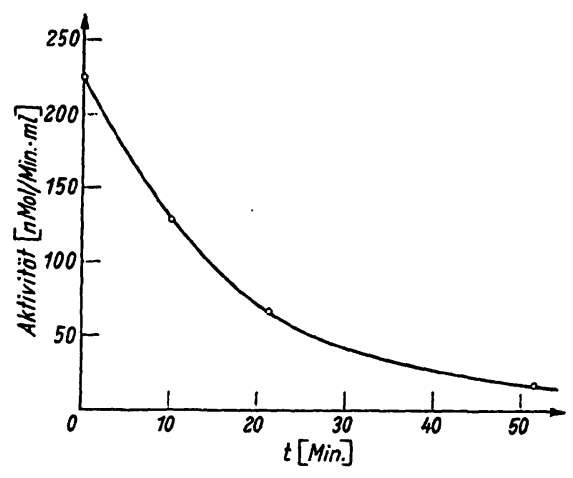

Abb. 7

5'-NTD-Aktivität (nMol 5'-AMP/Min. - ml hydrolysiert) in Abhängigkeit von der Dauer der Vorinkubation mit 1,5 mM EDTA ohne $\mathrm{Mg}^{++}$ Im 5'-NTD-Test: 0,1 mM 5'-AMP; 0,1 ml Serum mit sehr hohe $5^{\prime}$-NTD- und geringer AP-Aktivität; sonst wie Abb. 6

der günstigste Co-Faktor der 5'-NTD, nicht eingesetzt werden, da er mit EDTA einen sehr stabilen Komplex bildet (log Stabilitätskonstante $=13,4(36)$ ).

\section{Selektive 5'-NTD-Hemmung}

Auf Grund der Angaben von Ammed und Reis (17) nutzt Campbell (14) die selektive Hemmbarkeit der $5^{\prime}-\mathrm{NTD}$ durch $\mathrm{Ni}^{++}$aus und mißt die Serum-5'-NTD als Differenz der 5'-AMP-Hydrolyse ohne und mit $\mathrm{Ni}^{++}$-Ionen. Yoraussetzungen für die Richtigkeit dieser Methode sind, daß die 5'-NTD durch die verwendete Ni+t-Konzentration (10 mM) vollständig gehemmt und die AP nicht beeinflußt wird. Diese Bedingungen sind jedoch nicht erfüllt. Ebenso wie Ahmed und Reis (17) haben wir gefunden, daß $10 \mathrm{~mm} \mathrm{Ni++}$ die $5^{\prime}-\mathrm{NTD}$ Aktivität in einem Aortenmediaextrakt nur zu $90 \%$ hemmt. Auch im Serum wird die 5'-NTD, wie Abbildung 8 zeigt, nur zu 90\% gehemmt. Darüber hinaus kann auch die Serum-AP, besonders wenn sie zufolge osteoblastischer Knochenprozesse erhöht ist $(2,5,7)$, durch $\mathrm{Ni}^{++}$exheblich gehemmt werden. So haben SCHWARTZ und BODANSKY (15) nachgewiesen, daß eine aus menschlichem Knochen angereicherte AP durch $10 \mathrm{~mm} \mathrm{Ni}{ }^{++}$bei pH 7,5 zu 70\% gehemmt wird.

Bei unseren Versuchen zur Übertragung der kinetischen 5'-NTD-Bestimmung auf Serum hat sich außerdem die Differenzbestimmung mit $\mathrm{Ni}^{++}$verboten, weil $\mathrm{Ni}^{++}$ eine Zunahme der optischen Dichte bewirkt (Proteinfällung), die nach einigen Minuten auch als Trübung imponiert. Dieser Effekt kann durch $40 \mathrm{mMMg}^{++}$zwar weitgehend, aber nicht vollständig verhindert werden. Außerdem bildet $\mathrm{Ni}++$ mit den in Frage kommenden Puffern (Tris, Triäthanolamin, Glycylglycin) Komplexe $(36,37)$.

\section{Gleichreitige 5'-NTD-Aktivierung und AP-Hemmung durch Histidin}

Histidin aktiviert $5^{\prime}$-NTD und hemmt AP bei $\mathrm{pH} 8,5$ (15). Da das Ausmaß der Histidinhemmung sehr gering und außerdem je nach Herkunft der AP unterschiedlich ist (38), wird sich dieser Effekt für eine quantitative 5'-NTD-Bestimmung kaum ausnutzen lassen,

\section{Diskussion}

5'-Nucleotidase (5'-NTD), ein ubiquitäres Enzym, welches $5^{\prime}$-Mononucleotide in Nucleosid und Phosphat spaltet, würde sicherlich häufiger im Serum bestimmt werden, wenn die Methodik weniger aufwendig wäre. Schon die große Anzahl der in der Literatur beschriebenen Variationen zur 5'-N'TD-Bestimmung deutet darauf hin, daß es einen einfachen, sicheren Test bisher nicht gegeben hat. Wesentliche Nachteile liegen vor allem in der langen Inkubationsdauer, der ungenauen Abgrenzung der unspezifischen Phosphathydrolyse des Nucleotides und in der Endpunktbestimmung mittels Phosphatbestimmung. Wir haben die verschiedenen Literaturangaben methodisch überprüft und außerdem Versuche zur Verbesserung der 5'-NTD-Bestimmung gemacht, um daraus unter möglichst günstigen Bedingungen einen korrekten, sehr viel einfacheren und empfindlicheren Test zu entwickeln. Den naheliegenden Versuch, den von Kalckar (1.9) vorgeschlagenen UV-Test auf Serum zu übertragen, haben wir verwirklichen können und damit die Vorteile eines kinetischen Tests ausgenutzt (16).

$\mathrm{Zu}$ den im Ergebnisteil beschriebenen Untersuchungen möchten wir noch einige ergänzende Bemerkungen machen, wobei wir im wesentlichen die gleiche Reihenfolge einhalten.

Nach Conway und Cooke (39) kommt die AMPDesaminase im Serum nur in sehr geringen Méngen vor (etwa 0,05 Einheiten gegenüber 14 in Vollblut und 1145 in Skeletmuskulatur) und ist bei Substratkonzentrationen von $0,1 \mathrm{~mm}$ äußerst wenig aktiv. Diese Angaben stehen in gutem Einklang mit unseren Versuchen, auf Grund derer wir das. Vorkommen wesentlicher AMP-Desaminaseaktivitäten im Serum ausschließen können.

Bei $\mathrm{pH} 7,5$ zeigt AP unter sonst gleichen Bedingungen nur einen Bruchteil der Aktivität bei pH 9,3 (7, 15, 26, 27). Der durch ihre ungenaue Abgrenzung mögliche Fehler bei der $5^{\prime}$-NTD-Bestimmung ist daher geringer, als wenn die 5'-N'TD bei pH 9,3, ihrem zweiten Optimum in Gegenwart von $\mathrm{Mg}^{++}$(25), oder bei $\mathrm{pH} 8,5$, ihrem Optimum in Gegenwart von Aminosäuren und $\mathrm{Mg}^{++}(38,40)$ gemessen würde.

Die durch 0,5 mM Mn++ bewirkte starke Aktivierung der Serum-5'-NTD liegt im Bereich der durch optimale $\mathrm{Mg}^{++}$-Konzentration erreichbaren Aktivierung. Nach Young (2) wird die Serum-5'-N'TD durch $40 \mathrm{~mm} \mathrm{Mg} \mathrm{Mg}^{++}$ um das 3 fache, nach Schwartz und BoDansky (15) um das 2,3 fache aktiviert.

Die von uns bei. pH 7,5 mit $11 \mu \mathrm{M}$ 5'-AMP bestimmte Michaeliskonstante für Serum-5'-NTD liegt in derselben Größenordnung wie die in der Literatur für 5'-NTD anderer Herkunft beschriebenen $\mathrm{K}_{m}$-Werte $(23,24,25,32)$.

Im Bereich der optimalen Substratkonzentration von etwa $100 \mu \mathrm{M}$ (noch keine Substrathemmung) ist eine genauere Bestimmung der 5'-AMP-Hydrolyserate durch Phosphatbestimmung kaum mehr möglich (24, 38). 
Dagegen läßt sich im kinetischen UV-Test noch eine AMP-Spaltung von weniger als $1 \mathrm{nMol}$ registrieren. $\mathrm{Da}$ die 5'-NTD-Aktivität im Serum bisher nur mittels Phosphatbestimmung nach längerer Inkubation gemessen wurde, liegen die hierfür verwendeten $5^{\prime}$ AMP-Konzentrationen $(1-5 \mathrm{mM}(7,13,14)$ bereits in einem Bereich, für den wir Substrathemmung haben nachweisen können.

AP wird ebenfalls durch ihre Substrate gehemmt (21, 38, 41-43). Die Hemmkonzentrationen liegen höher als bei der $5^{\prime}$-NTD und schwanken je nach Substrat (43), pH (41-43) und Herkunft des Enzymes (38).

Daraus resultierende Fehler können wir umgehen durch Verwendung von $2^{\prime}-+3^{\prime}$-AMP als Vergleichssubstrat, dessen Hydrolyse gleich der des 5'-AMP im empfindlichen UV-Test gemessen werden kann, und dessen Konzentration wir daher mit $100 \mu \mathrm{M}$ so niedrig halten können, daß keine Substrathemmung auftritt.

Einen weiteren Anhalt dafür, daß sich $2^{\prime}-+3^{\prime}$-AMP als Vergleichssubstrat zur Bestimmung der unspezifischen Phosphathydrolyse besonders gut eignet, haben wir in den Arbeiten von KrNg und Delory $(33,34)$ gefunden, die mit mehreren AP-Präparationen eine große Anzahl von Substraten untersucht haben und folgende $\mathrm{Zu}$ sammenhänge aufzeigen: Je saurer ein Phosphatester ist, d. h. je niedriger sein $\mathrm{pK}_{1}$-Wert, um so weiter im Alkalischen liegt sein Spaltungsoptimum, um so schneller wird er bei diesem $\mathrm{pH}$ hydrolysiert und um so kleiner ist die Michaeliskonstante der AP.

In eine nach diesen Gesichtspunkten aufgestellte Reihe mehrerer Phosphatester haben wir die von KING und DELORY nicht untersuchten Substrate 2'-AMP, 3'-AMP und 5'-AMP nach ihren $\mathrm{pK}_{1}$-Werten (44) eingeordnet, die, einander eng benachbart, ebenso wie o-KresylPhosphat, zwischen denen von. Phenylphosphat und $\beta$-Glycerophosphat liegen, 5'-AMP wiederum $z$ wischen 3'-AMP und 2'-AMP (s. Tab. 1).

So wie REIs (26) gemäß der Theorie von KING und DELORY gezeigt hat, daß 5'-AMP von AP langsamer als das saurere Phenylphosphat und schneller als das basischere $\beta$-Glycerophosphat gespalten wird, dürfen wir annehmen, daß ein Gemisch von 2'-AMP un'd 3'AMP (2'- + 3'-AMP), weil sich das Mittel der $\mathrm{pK}_{1}$ Werte dem $\mathrm{pK}_{1}$-Wert von 5'-AMP annähert, durch $A P$ auch praktisch ebenso schnell hydrolysiert wird wie

Tab. 1

Physikalisch-chemische Daten für AP in Abhängigkeit vom Substrat, modifiziert nach DELORY und KING, erweitert um die Adeninmononucleotide

\begin{tabular}{|c|c|c|c|c|}
\hline Phosphatester & $\mathrm{pK}_{1}$ & $\begin{array}{c}\mathrm{pH}- \\
\text { Optimum }\end{array}$ & $\mathrm{Km}(\mathrm{mM})$ & $\begin{array}{c}\text { relative Hydro- } \\
\text { lyserate ( } \beta-\text { Gly- } \\
\text { cerophosphat } \\
=1)\end{array}$ \\
\hline \multirow{2}{*}{$\begin{array}{l}\text { Bromphenyl-P } \\
\text { Nitrophenyl-P } \\
\text { Phenyl-P } \\
\text { 3'-AMP } \\
\text { o-Kresyl-P } \\
\text { 5'-AMP } \\
\text { 2'-AMP } \\
\text { '-Alycero-P } \\
\text { a-Glycero-P } \\
\text { äthyl-P }\end{array}$} & \multirow{2}{*}{$\begin{array}{l}\mathbf{5 , 4 4} \\
\mathbf{5}, 70 \\
5,73 \\
5,88 \\
6,04 \\
6,05 \\
6,15 \\
6,34 \\
6,44 \\
6,45\end{array}$} & $\begin{array}{l}\mathbf{9 , 9 6} \\
\mathbf{9 , 8 0} \\
\mathbf{9 , 7 6}\end{array}$ & $\begin{array}{l}0,3 \\
0,5 \\
0,6\end{array}$ & $\begin{array}{l}3,4 \\
2,8 \\
2,4\end{array}$ \\
\hline & & $\begin{array}{l}8,82 \\
8,62 \\
8,08\end{array}$ & $\begin{array}{l}1,2 \\
1,4 \\
2,5\end{array}$ & $\begin{array}{l}1,0 \\
0,7 \\
0,3\end{array}$ \\
\hline
\end{tabular}

5'-AMP. Tatsächlich hat auch VolkIN (35) mit einer AP-Präparation aus Knochen gezeigt, daß bei $\mathrm{pH} 9,0$ die Nucleotide 2'-AMP, 3'-AMP und 5'-AMP gleich schnell gespalten werden. Auch nach unseren Versuchen liegen bei $\mathrm{pH}$ 9,8 die Hydrolyseraten von $2^{\prime}-+$ 3'-AMP und 5'-AMP benachbart zwischen denen von Phenylphosphat und $\beta$-Glycerophosphat (s. Abb. 4). Bei pH 7,5 halten die allein von AP gespaltenen Ester noch immer die gleiche Sequenz ein (s. Abb. 4); ihre bei $\mathrm{pH}$ 9,8 zweifellos noch deutlich verschiedenen Hydrolyseraten differieren jetzt aber nur noch sehr wenig -möglicherweise deshalb, weil dieser $\mathrm{pH}$ vom Spaltungsoptimum der leichter hydrolysierbaren Phosphatester schon so weit entfernt liegt, daß ihre Hydrolyserate derjenigen der basischeren Substrate nahekommt.

Obwohl wir bei pH 7,5 neben der immer vorhandenen spezifischen die unspezifische 5'-AMP-Hydrolyse durch Serum nicht direkt selektiv messen können, nehmen wir aus diesen Gründen an, daß sie, wie bei $\mathrm{pH} 9,8$, zwischen derjenigen des Phenylphosphates und $\operatorname{der} \operatorname{des} \beta$-Glycerophosphates liegt und durch Bestimmung der 2'$+3^{\prime}$-AMP-Spaltung gut abgeschätzt werden kann. Das gleiche dürfte für 0 -Kresylphosphat zutreffen, dessen $\mathrm{pK}_{1}$-Wert dem des 5'-AMP besonders nahekommt.

Unsere Versuche, in denen wir in Gegenwart von $40 \mathrm{~mm} \mathrm{Mg} \mathrm{Mg}^{++}$durch 1,5 mM EDTA AP fast vollständig hemmen, stehen in Einklang mit den Angaben von Mathies (45), daß die AP-Hemmung nicht auf $\mathrm{Mg}^{++}$, sondern auf $\mathrm{Zn}^{++}$-Bindung durch EDTA beruht.

Eine 5'-NTD-Hemmung durch $1 \mathrm{~mm}$ EDTA (s. Ergebnisse) ist auch von Center und Behal (28) beschrieben worden. Obwohl sie, wie wir gezeigt haben, in Gegenwart von $40 \mathrm{~mm} \mathrm{Mg}{ }^{++}$nicht auftritt, wird auch die Hemmung der Serum-5'-NTD nicht allein auf $\mathrm{Mg}^{++}$Mangel zurückzuführen sein, da HiLL und SAMmons (12) durch $16 \mathrm{~mm}$ EDTA auch in Gegenwart von $40 \mathrm{~mm} \mathrm{Mg}^{++}$vollständige 5'-NTD-Hemmung erreichen.

Durch $10 \mathrm{~mm} \mathrm{Ni++}$ wird, wie Schwartz und BoDANSKY (15) gezeigt haben, nicht nur die in Aorta und Serum vorkommende $5^{\prime}-\mathrm{NTD}$, sondern auch das aus Bullensperma stammende Enzym nur zu 90\% gehemmt. Eine Erhöhung der $\mathrm{Ni}^{++}$-Konzentration kann, wie Abbildung 8 zeigt, noch stärkere Hemmung hervorrufen, aber dann verstärkt sich die in dem von CAMpBELL (14) beschriebenen Testansatz (0,03M Veronal; $1 \mathrm{~mm} \mathrm{Mn}^{++}$) mit Serum immer auftretende Trübung. Die von HrLl und Sammons (12) mit $40 \mathrm{~mm} \mathrm{Mg}^{++}$ erzielte Verringerung dieser Trübungsreaktion durch Nickelionen wird mit $1 \mathrm{M} \mathrm{Mg}^{++}$vollständig; doch hemmt diese hohe $\mathrm{Mg}^{++}$Konzentration die 5'-NTD und AP erheblich (15).

Auch $\mathrm{NaCl}$ - oder Tris-Konzentrationen, die über der höchsten mit Veronal erreichbaren Konzentration liegen, verhindern eine Trübung. Tris setzt jedoch durch Komplexbildung die $\mathrm{Ni}^{++-K o n z e n t r a t i o n ~ h e r-~}$ ab (37), was auch erklären dürfte, daß LeviN und BoDANSKY (25) in 0,08M Tris nur eine 24proz. Hemmung der Bullensperma-5'-NTD durch $1 \mathrm{~mm} \mathrm{Ni}++$ fanden. 


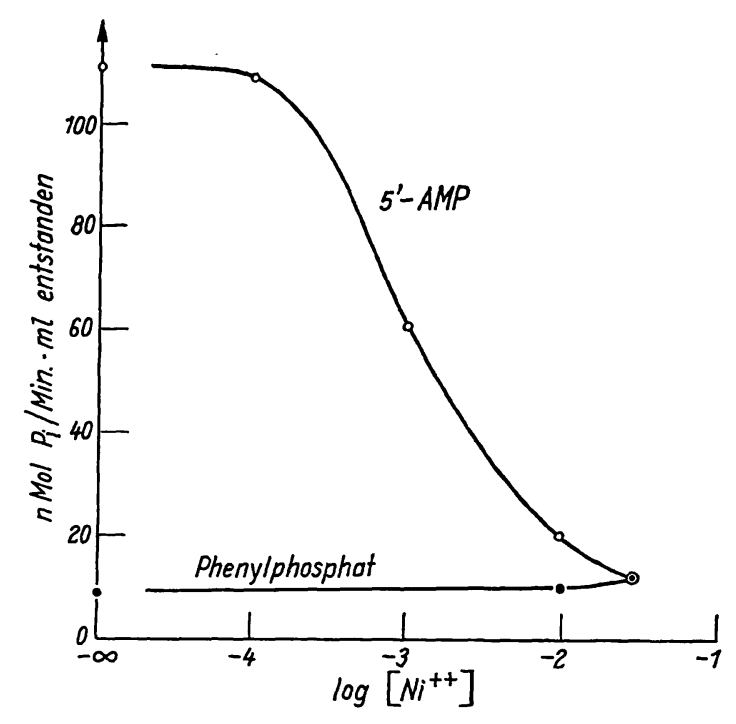

Abb. 8

Hemmung der Serum-5'-NTD durch $\mathrm{Ni}^{++}$. Testansatz (nach CAMPBELL): $1 \mathrm{mM}$ Substrat und $\mathrm{NiCl}_{2}$ wie bezeichnet; Vol. 2,0 $\mathrm{ml}$; Temp. $37^{\circ}$;
$0,03 \mathrm{M}$ Veronal $\mathrm{pH} 7,5 ; 1 \mathrm{~mm}$ MnSO $0,2 \mathrm{ml}$ Serum mit hoher 5 ;-
NTD- und AP-Aktivität: 30 Min. Inkubation

Der Gedanke, das in Gegenwart von ADA entstehende sekundäre Reaktionsprodukt $\mathrm{NH}_{4}^{+}$mit Glutamatdehydrogenase anhand der NADH-Oxydation zu bestimmen, liegt nahe $(46,47)$. Nachteile: Es wird nur $1 / 3$ der Empfindlichkeit des kinetischen Tests bei $265 \mathrm{~nm}$ erreicht. Außerdem haben wir selbst in Seren mit erhöhter 5'-NTD-Aktivität stets einen „Leerschleich“ gefunden, der die enzymbedingte Extinktionsabnahme weit übertrifft.
Wir haben zwar nur den ein Spektralphotometer voraussetzenden UV-Test in seinen technischen Einzelheiten ausgearbeitet und geprüft (s. 1. c.). Trotzdem möchten wir abschließend den Untersuchern, die auf eine Endpunktbestimmung mit Phosphatanalyse angewiesen sind, wenn der kinetische UV-Test nicht möglich ist (fehlendes Meßgerät, oder in Gewebsextrakten $\mathrm{zu}$ hohe optische Dichte, ADA-Inhibitoren, AMP-Desaminase), einen Vorschlag machen, die in der Literatur und in dieser Arbeit beschriebenen Ergebnisse zu einem möglichst empfindlichen und korrekten 5'-NTD-Test $z u$ vereinigen: In zwei Parallelansätzen mit 5'-AMP und 2'- + 3'-AMP wird die Phosphathydrolyse durch Serum bestimmt. Die Differenz ist ein $\mathrm{Maß}$ für die $5^{\prime}$-NTD-Aktivität $\left(1 \mathrm{mU}\left(37^{\circ}\right) / \mathrm{m} l=\right.$ $1 \mathrm{nMol} \mathrm{P}_{i}$ pro Min. pro $\mathrm{m} /$ ).

Ansatz I: In ein Zentrifugenglas werden einpipettiert: $1 ; 6 \mathrm{ml}$ $0,20 \mathrm{M}$ Tris, $\mathrm{pH} 7,5 ; 0,1 \mathrm{ml} 10 \mathrm{~mm} \mathrm{MnSO}_{4}$ (in $\mathrm{H}_{2} \mathrm{O}$ ); $0,1 \mathrm{ml}$ $20 \mathrm{~mm}$ 5'-AMP (mit NaOH auf pH 7,5 eingestellt). Etwa 5 Min. lang in ein Wasserbad von $37^{\circ}$ stellen, dann $0,2 \mathrm{ml}$ Serum zugeben und inkubieren. Nach genau $30 \mathrm{Min}$. Reaktion mit $2 \mathrm{ml} 10 \mathrm{proz}$. Trichloressigsäure stoppen. Zentrifugieren und $2 \mathrm{ml}$ des Überstandes zur Phosphatbestimmung verwenden.

Ansatz II: wird identisch behandelt, enthält aber anstelle von 5'-AMP 0,1 ml $20 \mathrm{~mm} 2^{\prime}-$ + 3'-AMP.

Ubersteigt die saure Prostata-Phosphatase $40 \mathrm{mU} / \mathrm{ml}$ (nach ANDERSCH und SzCYPINSKI (22)) $)^{2}$ ), so werden $0,2 \mathrm{ml}$ Tris durch $0,2 \mathrm{M} \mathrm{L}-$ Tartrat $^{2}$ ) ersetzt.

2) Merckotest „Saure Phosphatasec.

\section{Literatur}

1. Young, I. I., Clin. Res. Proc. 5, 213 (1957). - 2. Young, I. I., Ann. N. Y. Acad. Sci. 75, 357 (1958). - 3. Bardawill, C. und C. Chang, Canad. Med. Ass. J. 89,755 (1963). - 4. Vinnik, I. E., F. Kern und W. D. CORLEY, Gastroenterology, Baltimore 45, 492 (1963). - 5. Frenkel, M. und I. A. J. vaN TRIET, Israel med. J. 23, 18 (1964). - 6. Smith, K., H. H. VARON, G. J. RACE, D. L. Paulson, H. C. Urschel und J. T. Mallams, Cancer 19, 1281 (1966). - 7. Dixon, T. F. und M. Purdom, J. Clin. Path., London 7, 341 (1954). - 8. WACHSTEIN, M. und R. Srgismond, Amer. J. Clin. Path. 30, 523 (1958). - 9. Kowlessar, O. D., J. H. Pert, L. J. Haeffner und M. H. Sleisenger, Proc. Soc. Exper. Biol. Med., N. Y. 100, 191 (1959). - 10. Kowlessar, O. D., L. J. Haeffner, E. M. Riley und M. H. Sleisenger, Amer. J. Med. 31, 231 (1961). - 11. Salvetti, A., F. Ambrogi, C. Loni und B. Grassi, Progresso med., Napoli 21, 14 (1965). - 12. Hilr, P. G. und H. G. Sammons, Clinica chim. Acta, Amsterdam 13, 739 (1966). - 13. Schwartz, M. K. und O. Bodansky, Cancer 18, 886 (1965). - 14. Campbell, D. M., Biochem. J. 82, 34p (1962). 15. Schwartz, M. K. und O. Bodansky, Amer. J. Clin. Path. 42, 572 (1964). - 16. LeYrold, K., J. BeCKMaN und L. WersBECKER, diese Z. 7, 25 (1969) nachstehend. - 17. AfMED, $Z$. und J. L. Rers, Biochem. J. 69, 386 (1958). - 18. LohmanN, K. und L. Jendrassrk, Biochem. Zschr. 178, 419 (1926). - 19. KalCKar, H. M., J. biol. Chemistry 167, 445 (1947). - 20. RICK, W. und T. U. Hausamen, Z. analyt. Chem. 212, 267 (1965). - 21. Hausamen, T. U., R. Helger, W. RICK und W. Gross, Clinica chim. Acta, Amsterdam 15, 241 (1967). - 22. Andersch, M. A. und A. J. Szcyprnskr, Amer. J. Clin. Path. 17, 571 (1947). 23. Segal, H. L. und B. M. BRENNER, J. biol. Chemistry 235, 471 (1960). - 24. Ipata, P. L., Analyt. Biochem. 20, 30 (1967). -
25. Levin, S. J. und O. Bodansky, J. biol. Chemistry 241, 51 (1966). - 26. Rers, J. L., Biochem. J., 48, 548 (1951). — 27. Pearse, A. G. E. und J. L. Reis, Biochem. J., 50, 534 (1952). 28. Center, M. S. und F. J. Behat, Arch. Biochem. Biophysics 114, 414 (1966). - 29. Lineweaver, H. und K. D. Burk, J. Am. chem. Soc. 56, 658 (1934). - 30. Ahmed, Z. und E. J. King, Biochim. biophysica Acta, Amsterdam 34, 313 (1959). - 31. REIs, J. L., Biochem. J. 46, xxi (1950). - 32. Song, C. S. und O. BoDANSkY, Biochem. J. 101, 5c (1966). - 33. KING, E. J. und G. E. DelORY, Biochem. J. 33, 1185 (1939). - 34. DeLoki, G. E. und E. J. KNvG, Biochem. J. 37, 547 (1943). - 35. Vorkin, E., in: Colowick-Kaplan (Hrsg.): Methods in Enzymology II, S. 539. Academic Press Inc., Publishers, New York (1955). - 36. MARTELI, A. E. und M. Carvin, Die Chemie der Metallchelat-Verbindungen, S. 462. Verlag Chemie, Weinheim (1958). - 37. Hanlon, D. P., D. S. Watt und E. W. Westread, Analyt. Biochem. 16, 225 (1966). - 38. Bodansky, O. und M. K. SGhwartz, J. biol. Chemistry 238, 3420 (1963). - 39. Conway, E. J. und R. Cooke, Biochem. J. 33, 479 (1939). - 40. HEPpEL, L. A. und R. J. Hrimoe, J. biol. Chemistry 188, 665 (1951). 41. Ross, M. H., J. O. ELY und J. G. ARCHER, J. biol. Chemistry 192, 561 (1951). - 42. Morton, R. K., Biochem. J. 65, 674 (1957). - 43. Motzok, I., Biochem. J. 72, 169 (1959). - 44. Alberty, R. A., R. M. SMIth und R. M. Bock, J. biol. Chemistry 193, 425 (1951). - 45. Mathies, J. C., J. biol. Chemistry 233, 1121 (1958). - 46. Kirsten, E., C. Gerez und R. Kirsten, Biochem. Zschr. 337, 312 (1963). - 47. Lorenz, W., J. Kusche und E. WerLE, Biochemische Analytik, Kurzreferat der Tagung vom 29.4.-2.5. 1968 in München. S. 16. Springer-Verlag, Berlin-Heidelberg-New York, J. F. Bergmann München (1968).

Dr. K. Leybold 23 Kiel Metzstr. 53-57 